\title{
The involvement of a primary care doctor in the process of pain treatment and the quality of life of patients
}

\author{
MATEUSZ SOBIESKI 1, A, B, D-F , ALEKSANDRA KORZENIEWSKA ${ }^{1,2, ~ A, ~ C-E, ~}$ \\ ORCID ID: 0000-0002-1371-1659 ORCID ID: 0000-0002-4619-2066 \\ URSZULA TERESA GRATA-BORKOWSKA ${ }^{1, \mathrm{E}}$ \\ ORCID ID: 0000-0003-3783-0481
}

${ }^{1}$ Department of Family Medicine, Wroclaw Medical University, Poland

${ }^{2}$ SWPS University of Social Sciences and Humanities, Wroclaw, Poland

A - Study Design, B - Data Collection, C - Statistical Analysis, D - Data Interpretation, E - Manuscript Preparation, F - Literature Search, G - Funds Collection

Summary Background. When the pain felt by the patient loses its alarming function, it becomes an element significantly reducing the quality of life. Due to the frequency of occurrence of pain in the population and its impact on various aspects of patients' lives, this is a problem that doctors often encounter in primary care clinics.

Objectives. The aim of this study was to show the relationship between the involvement of the primary care physician in the therapeutic process of pain treatment and the level of subjective and objective quality of life of patients. Efforts were also made to review the situation regarding the treatment of pain with pharmacological and non-pharmacological methods used by both patients and doctors. Material and methods. The study included 191 patients and 37 doctors. Separate surveys were prepared for both groups. Additionally, among patients, an EQ-5D-5L questionnaire was carried out. The collected data was subjected to statistical analysis using the SPSS 25 program.

Results. The involvement of a doctor in the treatment of pain moderately correlates with a higher level of quality of life, both subjective and objective. There was no correlation between satisfaction with the physician's involvement in the therapeutic process and the level of experienced pain.

Conclusions. Although the primary care doctor has a limited ability to control the therapeutic process of his patients' pain, it is important to be involved in the treatment process, because it is associated with an increased quality of life, patient's satisfaction with the primary care doctor and a reduced level of pain.

Key words: primary health care, chronic pain, quality of life.

Sobieski M, Korzeniewska A, Grata-Borkowska UT. The involvement of a primary care doctor in the process of pain treatment and the quality of life of patients. Fam Med Prim Care Rev 2020; 22(3): 212-215, doi: https://doi.org/10.5114/fmpcr.2020.98248.

\section{Background}

According to the International Society for the Study of Pain (IASP), pain is defined as "an unpleasant sensory and emotional experience associated with actual or potential tissue damage, or described in terms of such damage" [1]. Pain that fulfils the criteria of this definition plays an alarming role and informs about pathological conditions that affect the patient's health. Due to this, the patient is willing to find the cause of the ailment and its treatment. However, if the pain extends beyond the expected period of healing (most commonly used arbitrary markers are 3 months and 6 months since onset), it ceases to be a warning sign and becomes chronic pain [1]. Both acute and chronic pain significantly affect the quality of life of patients, and coexistence as a symptom in the vast majority of acute and chronic diseases is one of the main reasons for patient visits to both emergency departments and primary care clinics [2-4].

Risk factors for developing chronic pain include [5-8]:

- $\quad$ sex (female),

- older age,

- lower level of education,

- lower income level,

- loneliness (widowhood, divorced),

- obesity or underweight,

- cardiovascular and respiratory diseases,

- physical work,

- nicotinism.
The most common causes of chronic pain are osteoarthritis $(47 \%)$, spinal disc herniation $(21 \%)$, osteoporosis (15\%), migraine and other headaches (8\%), peripheral vascular disease $(7 \%)$ and rheumatoid arthritis (5\%) [6]. Chronic lower back pain results in the highest amount of years lost due to disability factor for all diseases assessed in the Global Burden Disease Study, which is up to 146 million years globally [6].

It is estimated that $19 \%$ of Europe's population suffers from different chronic pain syndromes, but the incidence varies between countries - from $11 \%$ in Spain to $30 \%$ in Norway - howev$\mathrm{er}$, this data may be significantly underestimated due to the fact of the subjectivity and multidimensionality of symptoms [9]. Online cohort studies from 2008 conducted in the five largest European countries - Germany, France, Spain, Great Britain and Italy - indicate that $20.3 \%$ of the population suffered from pain in the month preceding the studies. In this group, more than $22 \%$ respondents described the pain as strong, and over $59 \%$ as moderate [5]. In turn, more recent studies, also concerning the population of the European Union, conducted by Pain Alliance Europe (PAE), indicate that the problem of chronic pain affects more than $20 \%$ of adults, of whom $34 \%$ describe this pain as strong [10].

It is estimated that treating the pain and its complications costs about 300 billion EUR per year [11]. Patients suffering from strong and moderate pain are less productive and quit their jobs more often. The quality of life in this group is also significantly 
lower than in patients with rectal or prostate cancer. These patients also use medical services more often than average - the frequency of visits in primary care clinics and hospitals increases linearly as the level of pain increases [12].

When patients experience pain, they usually turn to their family doctors for help. Studies on the European population show that $38 \%$ of patients with chronic pain are managed by family doctors, less often in hospitals $(30 \%)$ or specialist clinics (11\%) [10]. The family doctor then becomes responsible for finding a relevant medical proceeding. Usually, patients with acute pain, which is then the main reason for visiting a doctor, report the presence of pain themselves. Although, patients with chronic pain often underestimate their ailments, putting the blame on their age or the presence of comorbidities, which requires extra vigilance.

The duration of pain treatment by a family doctor varies depending on the country. In European countries, 58.2\% of patients with pain are treated for more than six months. $54.7 \%$ of patients were referred by a family doctor to other specialists or were offered to use other methods of pain treatment [10]. An increasing number of patients using only over-the-counter painkillers (in $2013-32.6 \%$, in $2017-41.7 \%$ ) and a decreasing number of patients using only prescription drugs has been observed (from $33.2 \%$ to $18.4 \%$ ) [13].

\section{Objectives}

An analysis of the cited literature indicates the significance of the problem of pain and its relationship to the quality of life of patients. The aim of the study was to find the relationship between the perceived quality of family doctor's care and quality of a patient's life. A review of pain management methods used by patients and doctors was also made. The following research hypotheses were made:

1. There is a negative relationship between the level of pain experienced by patients and the level of the quality of life.

2. There is a positive relationship between the subjective sense of a patient's health and the level of the quality of life.

3. There is a positive relationship between the primary care doctor's involvement in the pain treatment process and the subjective sense of a patient's health.

4. There is a positive relationship between a patient's satisfaction with their primary care doctor and the level of pain experienced by the patient.

\section{Material and methods}

The data was collected using anonymous electronic and paper surveys.

The study involved 191 primary care patients in the range of 16 to 82 years (average age 42.96, SD: 18.65) and 37 doctors in the range of 27 to 53 years (average age 32, SD: 5.73) providing services in primary care clinics. A separate survey was prepared for each group. The patient survey contained 15 questions, including the Visual Analogue Score (VAS) scale for assessing pain levels and the EQ-5D-5L questionnaire for measuring the quality of life. The survey for doctors contained 26 questions about their beliefs regarding their competence in pain management, attitude towards specific therapeutic methods and checking the level of knowledge about pain treatment. The obtained results were subjected to statistical analysis using the SPSS 25 statistical package. Correlation analysis was performed using the Pearson $r$ factor. The statistical significance level is 0.05 for all endpoints included.

Due to the method of data collection, it was not necessary to obtain the approval of the institutional review board.

\section{Results}

Among the examined patients, $25.1 \%(n=48)$ of them suffer from pain every day, $14.7 \%(n=28)$ - at least twice a week, $18.8 \%(n=36)$ - at least once a week, and another $24.6 \%$ $(n=47)-$ at least once a month. The frequency of pain relief methods that patients use is presented in Table 1. $11 \%(n=21)$ of them use three or more methods together.

\begin{tabular}{|c|c|c|}
\hline Method & $\begin{array}{l}\text { Frequency of } \\
\text { use among } \\
\text { patients }\end{array}$ & $\begin{array}{l}\text { Used as the } \\
\text { only method }\end{array}$ \\
\hline Over-the-counter painkillers & $67.5 \%(n=129)$ & $27.7 \%(n=53)$ \\
\hline $\begin{array}{l}\text { Physical exercises, stretch- } \\
\text { ing, massaging the painful } \\
\text { area }\end{array}$ & $45 \%(n=86)$ & $16.8 \%(n=32)$ \\
\hline $\begin{array}{l}\text { Applying something hot/ } \\
\text { /cold }\end{array}$ & $15.7 \%(n=30)$ & $1 \%(n=2)$ \\
\hline Attempt to fall asleep & $21.5 \%(n=41)$ & $3.1 \%(n=6)$ \\
\hline $\begin{array}{l}\text { Home methods (alcohol, } \\
\text { herbs, etc.) }\end{array}$ & $8.4 \%(n=16)$ & $3.1 \%(n=6)$ \\
\hline
\end{tabular}

$36.6 \%(n=70)$ of patients say their family doctor asks about pain on their own account, and only $20.9 \%(n=40)$ say that this question is asked at each consultation. Similarly, only $32.4 \%$ ( $n=12$ ) of doctors say that they used to ask their patients about their pain at each appointment. The greatest discrepancy is between the opinions of doctors and patients concerning the use of the pain rating scale $-37.8 \%(n=14)$ of family doctors declare that they use different scales to measure pain, and only $8.9 \%$ $(n=17)$ of patients had performed a pain assessment on the VAS scale by their family doctor.

Painkillers are the most common method of treating pain among primary care patients $-51.3 \%(n=98)$ of them reported that they were recommended to them. The most common way of administration was oral ( $42.9 \%(n=82)$ of all patients) then topical (i.e. gels or ointments; $18.8 \%(n=36)$ of patients), and the least often - injections $(6.3 \%(n=12))$ or plasters with painkiller $(5.2 \%(n=10))$. Antidepressants are the most commonly prescribed co-analgesics in primary health care $-67.6 \%(n=25)$ of family doctors use them when appropriate indications for their use exist; antiepileptic drugs (59.5\% $(n=22))$ and corticosteroids $(37.8 \%(n=14))$ are used less frequently. There was also a negative correlation between the family doctor's recommendation and the level of pain experienced by patients ( $p=$ $0.028 ; r=-0.159$ ).

Non-pharmacological methods were used less frequently - the recommendation for their use was given to $30.8 \%(n=59)$ of patients. Despite few objections concerning their effectiveness, side effects or cost-benefit ratio (Table 2), they were often recommended only by half of the doctors surveyed. The frequency of patients using non-pharmacological methods recommended by their primary care doctors is also shown in Table 2 .

47.1\% $(n=90)$ of patients received referrals to different specialists because of their pain. Most often, patients were referred to orthopaedic $(24.1 \%$ of all patients $(n=46))$, neurological $(15.2 \%(n=29))$ and rheumatological $(12.6 \%(n=24))$ clinics. Only $4.2 \%(n=8)$ of patients were referred to a pain clinic. A negative weak correlation was also found between the referral to a specialist clinic by a family doctor and the level of pain experienced by patients $(p=0.002 ; r=-0.223)$.

Only $48.6 \%(n=93)$ of patients were satisfied with their pain management by family doctors. However, as many as $91.9 \%$ ( $n=$ 34) of family doctors said that they treated their patients suffering from pain with sufficient empathy and understanding. $64.7 \%$ $(n=24)$ of doctors reported that most patients could be cured of 


\begin{tabular}{|l|l|l|l|}
\hline Table 2. Frequency of non-pharmacological methods of treating pain \\
\hline Non-pharmacological treatment & $\begin{array}{l}\text { Percentage of doctors } \\
\text { who recommend the } \\
\text { method }\end{array}$ & $\begin{array}{l}\text { Percentage of doctors } \\
\text { who have objections to } \\
\text { the method }\end{array}$ & $\begin{array}{l}\text { Percentage of patients } \\
\text { using the method }\end{array}$ \\
\hline Physiotherapy & $86.5 \%(n=32)$ & $0 \%(n=0)$ & $25.1 \%(n=48)$ \\
\hline Regional nerve block & $56.7 \%(n=21)$ & $10.8 \%(n=4)$ & $1.6 \%(n=3)$ \\
\hline Psychological help (e.g. psychotherapy) & $54.1 \%(n=20)$ & $0 \%(n=0)$ & $1.6 \%(n=3)$ \\
\hline Relaxation & $45.9 \%(n=17)$ & $0 \%(n=0)$ & $5.2 \%(n=10)$ \\
\hline Transcutaneous electrical nerve stimulation (TENS) & $51.4 \%(n=19)$ & $5.4 \%(n=2)$ & $0.5 \%(n=1)$ \\
\hline Acupuncture & $37.8 \%(n=14)$ & $21.6 \%(n=8)$ & $0.5 \%(n=1)$ \\
\hline Heat treatment & $56.7 \%(n=21)$ & $8.1 \%(n=3)$ & $3.1 \%(n=6)$ \\
\hline Cryotherapy & $70.3 \%(n=26)$ & $5.4 \%(n=2)$ & $7.3 \%(n=14)$ \\
\hline
\end{tabular}

pain, and $86.5 \%(n=32)$ of them said that the patient is responsible for the final process of pain therapy. Despite this, $48.6 \%$ $(n=18)$ of doctors decided to refuse their patient an increase in the dosage of a painkiller.

A significant negative relationship between the perceived level of pain and the level of the patient's quality of life $(p<$ $0.001, r=-0.377$ ) and a positive relationship between the subjective sense of health and the level of a patient's quality of life $(p<0.001, r=0.527)$ were found. A positive correlation was also found between three of the four analysed aspects of the doctor's involvement in the process of treating pain with a subjective sense of the patient's health. The results are presented in Table 3.

\begin{tabular}{|c|c|}
\hline & $\begin{array}{l}\text { Subjective sense of } \\
\text { the patient's health }\end{array}$ \\
\hline $\begin{array}{l}\text { Does the doctor ask for the patient's } \\
\text { pain on his own account? }\end{array}$ & $p=0.025, r=0.162$ \\
\hline $\begin{array}{l}\text { Does the doctor recommend using } \\
\text { pharmacological methods in pain } \\
\text { treatment? }\end{array}$ & $p<0.001, r=0.308$ \\
\hline $\begin{array}{l}\text { Does the doctor refer the patient to } \\
\text { a specialist? }\end{array}$ & $p<0.001, r=0.261$ \\
\hline $\begin{array}{l}\text { Does the doctor recommend using } \\
\text { non-pharmacological methods in pain } \\
\text { treatment? }\end{array}$ & $p=0.610 ; r=0.037$ \\
\hline
\end{tabular}

Table 4. Correlation between aspects of the doctor's

involvement in the process of treating pain with the patient's satisfaction positively with ment. The results are presented in Table 4.

\section{Discussion}

The obtained results confirm that the involvement of the primary care doctor is associated with an increase in the level of the quality of life. The objective indicator of the quality of life significantly correlates only with the doctor's recommendation of using pharmacological treatment and referring the patient to specialist clinics and do not correlate with the other investigated aspects. However, the subjective indicator of quality of life correlates with the fact that the patient feels the doctor's involvement. This discrepancy may be due to the fact that the EQ-5D-5L scale, used in the study, does not contain questions about aspects of social functioning and interpersonal relations, but only focuses on somatic aspects of life. Hence, the objective indicator of the level of quality of life increases after the use of painkillers and referring the patient to specialist care, because the level of pain is then significantly reduced. In turn, the subjective indicator may contain various aspects of human life, together with social interactions, which is also the care shown by the doctor [14]. For many older patients, the family doctor is one of the few people known to them with whom they enter into a regular relationship and to whom they can entrust their ailments.

The level of patient satisfaction with their primary care doctors correlates with all activities understood as doctors' involvement - i.e. asking about the level of pain, proposing pharmacological and non-pharmacological methods and issuing referrals to specialist clinics, but it is not associated with the level of indicators of quality of life and the level of pain. A possible explanation is that doctors are evaluated by patients not only through their effectiveness, but also through their efforts and care.

An unsatisfactory result in the context of pain treatment and prevention is the percentage of doctors who ask their patients about pain upon their own initiative at each appointment. Therefore, the use of questions about pain can be treated as a form of active prevention which will prevent further development of diseases, thus limiting the development of pain and a decrease in the level of quality of life of patients. The question about pain upon their own initiative is also important, because some patients determine age or comorbidities as the cause of discomfort and find it irrelevant to report it to the doctor.

Despite the lack of objections to the use of non-pharmacological methods of treating pain by doctors, they are rarely used by patients. There was also a discrepancy between the beliefs of doctors and patients about the frequency of offering these methods. While the difference in beliefs may be the result of information overload during the visit or many other factors, non-use of these methods may be due to limited availability or the prolonged time of therapy. The high cost of this form of therapy may also be a possible barrier. Therefore, it seems that drugs are a faster and cheaper method of pain treatment, despite their symptomatic effect and the possibility of side effects. 


\section{Conclusions}

The involvement of a primary care doctor in the process of treating patient pain is associated with many benefits for the patient and the doctor. Demonstrating an active attitude, consisting in asking the patient about pain upon their own initiative, use of pharmacological and non-pharmacological therapies and referring the patient to specialist clinics is associated with an increased level of quality of life, a reduced level of pain felt by the patient and an increase in the patient's satisfaction with their primary care doctor.

Source of funding: This work was funded from the authors' own resources.

Conflicts of interest: The authors declare no conflicts of interest.

\section{References}

1. Loeser JD, Treede RD. The Kyoto protocol of IASP Basic Pain Terminology. Pain 2008; 137: 473-477.

2. Niv D, Kreitler S. Pain and quality of life. Pain Practice 2001; 1: 150-161.

3. Bujnowska-Fedak MM, Sapilak BJ, Steciwko A. Epidemiologia schorzeń i struktura zachorowań w praktyce lekarza rodzinnego. Fam Med Prim Care Rev 2011; 13(2): 135-139 (in Polish).

4. Sauver JL, Warner DO, Yawn BP, et al. Why patients visit their doctors: assessing the most prevalent conditions in a defined American population. Mayo Clin Proc 2013; 88: 56-67.

5. Langley PC. The prevalence, correlates and treatment of pain in the European Union. Curr Med Res Opin 2011; 27: 463-480.

6. Rice ASC, Smith BH, Blyth FM. Pain and the global burden of disease. Pain 2016; 157: 791-796.

7. Vos T, Barber R, Bell B, et al. Global, regional, and national incidence, prevalence, and years lived with disability for 301 acute and chronic diseases and injuries in 188 countries, 1990-2013: a systematic analysis for the Global Burden of Disease Study. Lancet 2013; 386: 743-800.

8. Kvalheim S, Sandven I, Hagen K, et al. Smoking as a risk factor for chronic musculoskeletal complaints is influenced by age. The HUNT Study. Pain 2013; 154: 1073-1079.

9. Breivik H, Collett B, Ventafridda V, et al. Survey of chronic pain in Europe: Prevalence, impact on daily life, and treatment. Eur J Pain 2006; 10: 287-333.

10. Pain Alliance Europe. Survey on Chronic Pain. Brussels: Pain Alliance Europe 2017. Available from URL: https://www.pae-eu.eu/wpcontent/uploads/2017/12/PAE-Survey-on-Chronic-Pain-June-2017.pdf.

11. Phillips CJ. Economic burden of chronic pain. Expert Rev Pharmacoecon Outcomes Res 2006; 6(5):591-601, doi: 10.1586/14737167.6.5.591.

12. European Pain Federation. Pain Proposal. Improving the current and future management of chronic pain. Brussels: European Pain Federation 2016. Avaliable from URL: https://europeanpainfederation.eu/wp-content/uploads/2016/06/pain_proposal.pdf.

13. Kantar Health. The Global Health and Wellness Survey Report. New York: Kantar Health 2018. Available from URL: https://www.kantarhealth.com/docs/white-papers/2018-ghwr-exec-summary.pdf?sfvrsn=36c8d3b0_2.

14. Ong LML, Visser MRM, Lammes FB, et al. Doctor-patient communication and cancer patients' quality of life and satisfaction. Patient Educ Couns 2000; 41(2): 145-156, doi: 10.1016/s0738-3991(99)00108-1.

Tables: 4

Figures: 0

References: 14

Received: 05.05.2020

Reviewed: 12.05.2020

Accepted: 15.05.2020

Address for correspondence:

Urszula Grata-Borkowska, MD

Katedra i Zaklad Medycyny Rodzinnej

Uniwersytet Medyczny

ul. Syrokomli 1

51-141 Wrocław

Polska

Tel.: +48 71 326-68-73

E-mail: urszula.grata-borkowska@umed.wroc.pl 